\title{
The repeatability of interleukin-6, tumor necrosis factor- $\alpha$, and $C$-reactive protein in COPD patients over one year
}

\author{
Umme Kolsum \\ Kay Roy \\ Cerys Starkey \\ Zoë Borrill \\ Nick Truman \\ Jørgen Vestbo \\ Dave Singh
}

North West Lung Research Centre, University of Manchester, South Manchester University Hospitals Trust, Wythenshawe, Manchester, UK

Correspondence: Umme Kolsum North West Lung Research Centre, University of Manchester, South Manchester University Hospitals Trust, Wythenshawe, Manchester, UK, M23 9LT Tel +44 I6I 9464065

$\mathrm{Fax}+44$ I6I 9461459

Email ukolsum@meu.org.uk
Background: Many of the systemic manifestations of chronic obstructive pulmonary disease (COPD) are mediated through increased systemic levels of inflammatory proteins. We assessed the long term repeatability of Interleukin-6 (IL-6), tumor necrosis factor- $\alpha$ (TNF- $\alpha$ ), and C-reactive protein (CRP) over one year and examined the relationships between these systemic markers in COPD.

Methods: Fifty-eight stable COPD patients completed a baseline and one-year visit. Serum IL-6, plasma CRP, and plasma TNF- $\alpha$ were measured. Repeatability was expressed by intraclass correlation coefficient $\left(\mathrm{R}_{\mathrm{i}}\right)$ and the Bland-Altman method. Pearson correlations were used to determine the relationships between the systemic markers at both visits.

Results: There was moderate repeatability with a very high degree of statistical significance ( $p \leq 0.001$ ) between the two visits for all the systemic biomarkers (IL-6, CRP, and TNF- $\alpha$ ). CRP was significantly associated with IL-6 at both visits $(r=0.55, p=0.0001, r=0.51, p=0.0002$, respectively). There were no other significant associations between the systemic markers at either of the visits.

Conclusions: Systemic inflammatory biomarkers IL-6, CRP, and TNF- $\alpha$ were moderately repeatable over a twelve month period in COPD patients. We have also shown that a robust and repeatable association between IL- 6 and CRP exists.

Keywords: interleukin- 6 , tumor necrosis factor- $\alpha$, C-reactive protein, repeatability, COPD

\section{Introduction}

Chronic obstructive pulmonary disease (COPD) is a heterogeneous condition characterized by progressive airway inflammation. ${ }^{1}$ It is well recognized that systemic manifestations are also a key component of COPD. These include increased levels of inflammation in the blood, ${ }^{2,3}$ muscle inflammation and wasting, ${ }^{4,5}$ cardiovascular disease, ${ }^{6}$ and osteoporosis. ${ }^{7}$ There is much interest in the use of biomarkers of systemic inflammation in COPD, as these may have possible applications in disease phenotyping, monitoring of disease progression or exacerbations, and measuring the effects of therapeutic interventions.

It is believed that many of the systemic manifestations of COPD are mediated through increased systemic levels of inflammatory proteins such as interleukin-6 (IL-6), tumor necrosis factor- $\alpha$ (TNF- $\alpha$ ) and C-reactive protein (CRP). ${ }^{2-4,8-12}$ CRP is a commonly used biomarker of systemic inflammation in patients with COPD. Plasma CRP levels are increased in COPD patients ${ }^{2,3}$ and are associated with increased mortality. ${ }^{13,14} \mathrm{CRP}$ levels are predictive of cardiovascular risk, ${ }^{15,16}$ and in patients with COPD also independently predict death due to COPD. ${ }^{13} \mathrm{CRP}$ is also related to other important clinical outcomes including exercise tolerance, ${ }^{2,17}$ health status, ${ }^{2}$ and muscle strength. ${ }^{3}$ CRP is regulated by IL-6, as this cytokine can initiate an acute phase response through the induction of acute phase proteins including CRP in hepatocytes. ${ }^{18}$ 
Consequently, it has been shown that IL-6 and CRP levels correlate in COPD patients. ${ }^{2,3,19,20}$

TNF- $\alpha$ has been shown to play a central role in the muscle wasting and weight loss seen in COPD patients ${ }^{9,21,22}$ and several studies have demonstrated increased levels of TNF- $\alpha$ and its receptors in the circulation of COPD patients. ${ }^{4,8,11,12,21}$ There is some evidence that TNF- $\alpha$ levels are related to levels of IL- $6^{3,19,23}$ and CRP, ${ }^{3}$ although this has not been reported in all studies. ${ }^{2}$

CRP has previously been shown in a study by Pinto and colleagues ${ }^{17}$ to be repeatable over a 17 month period and even more recently both IL-6 and CRP have been shown to be repeatable over a six month period. ${ }^{24}$ However longer term studies of the repeatability of IL- 6 and TNF- $\alpha$ are lacking. The repeatability of systemic biomarkers is an important issue, as those with increased variability will have less utility in clinical practice or research. Studies analyzing longer term repeatability are needed if systemic biomarkers are going to be used in long term observational studies or clinical trials of therapeutic interventions.

The main aims of this study were to 1) assess the long term repeatability of systemic biomarkers of inflammation (CRP, TNF- $\alpha$, IL-6) in COPD patients over one year, 2) to examine the relationships between these systemic markers and confirm the results of previous studies in this area.

\section{Methods}

\section{Subjects}

Ninety-four stable patients were initially recruited into this single centre study from primary care by media advertising to the study at baseline (2004-2005), however only 58 patients returned for their follow up assessment (2005-2006). The 36 patients were lost to follow up as they either had withdrawn their consent or had not returned for their visit within the one-year timeframe. COPD was diagnosed according to current Global Initiative for Chronic Obstructive Lung Disease (GOLD) guidelines, ${ }^{1}$ based on a smoking history of at least 10 pack-years with typical symptoms (one or more of productive cough, breathlessness, and wheeze) and evidence of airflow obstruction. Patients with a clinical history of asthma, alpha-1-antitrypsin deficiency, an exacerbation or any change in their COPD therapy within four weeks of the study at the baseline and the one-year visit, or a history of lung cancer were excluded. Written informed consent was obtained and the local ethics committee approved the study.

\section{Study design}

Spirometry, sputum induction, and peripheral blood sampling were performed at the baseline visit and then repeated one year later. Sputum differential cell counts were performed and IL- 8 was measured in the sputum supernatant to characterize airway inflammatory biomarkers. Serum IL-6, plasma CRP, and plasma TNF- $\alpha$ were measured at both visits as biomarkers of systemic inflammation. Height was measured to the nearest $\mathrm{cm}$ and weight to the nearest $100 \mathrm{gm}$. Body mass index (BMI) was calculated as weight in $\mathrm{kg}$ divided by squared height in meters.

\section{Spirometry}

Maximum expiratory flow volume measurements were performed using the spirometry system on the MasterScreen (Jaeger GmbH, Würzburg, Germany). Forced expiratory volume in one second $\left(\mathrm{FEV}_{1}\right)$ and forced vital capacity (FVC) readings were performed in triplicate. Spirometry during sputum induction was performed with a Vitalograph spirometer (Vitalograph, Buckinghamshire, UK). The equipment was calibrated daily according to the manufacturer's instructions.

\section{Plasma and serum assays}

Plasma and serum were obtained from peripheral blood samples by centrifugation for 15 minutes, at $1500 \mathrm{~g}$ and at $4{ }^{\circ} \mathrm{C}$ or ambient temperature, respectively. Plasma and serum samples were stored at $-80{ }^{\circ} \mathrm{C}$ until analysis. Plasma TNF- $\alpha$ and serum IL- 6 was measured by high sensitivity ELISA (Quantikine, R\&D Systems Europe, Oxon, UK) with a lower limit of detection of $0.5 \mathrm{pg} / \mathrm{ml}$ and $0.156 \mathrm{pg} / \mathrm{ml}$ respectively. Serum was used for the IL-6 assay as there was insufficient plasma available from all patients. Plasma CRP was measured by high sensitivity particle-enhanced immunonephelometry (Cardiophase; BN systems, Dade Behring, Newark, NJ, USA) with a lower limit of detection of $0.175 \mathrm{mg} / \mathrm{L}$.

\section{Statistical analysis}

The Kolmogorov - Smirnov test determined normality of the data and nonparametric data were natural log transformed. Naturally log-transformed data was therefore used for IL-6, CRP, and TNF- $\alpha$ for our anlaysis.

Paired t test was performed to determine the mean differences between the baseline and one-year visit. Repeatability was expressed as an intraclass correlation coefficient (ICC) $\left[\mathrm{R}_{\mathrm{i}}=\right.$ between-subject variance/ (within- + betweensubject variance)]. $\mathrm{P}<0.05$ was considered statistically significant. $\mathrm{R}_{\mathrm{i}}$ values of 0 to 0.2 are usually interpreted to indicate slight repeatability, 0.21 to 0.40 to indicate fair repeatability, 0.41 to 0.60 to indicate moderate repeatability, 
0.61 to 0.8 to indicate good repeatability, and 0.81 to 1.00 to indicate very good repeatability. Graphical representation of repeatability between the two visits were reported using the Bland - Altman method. ${ }^{30}$ The limits of agreement are expressed as \pm 2 standard deviations (SD) of the mean of differences betweeen the two measurements within which $95 \%$ of the repeated measures are expected to lie and for our naturally log-transformed data the limits of agreement were antilogged to express the fold changes expected over a one-year period.

Pearson correlations were used to determine the relationships between the systemic markers at both the baseline and one-year visit. Statistical analyses were performed using SPSS (SPSS Inc., Chicago, IL, USA) and GraphPad (GraphPad Software, Inc., La Jolla, CA, USA) software.

Previous publications studying the repeatability of sputum biomarkers, ${ }^{25-29}$ plasma IL- $6,{ }^{24}$ and $\mathrm{CRP}^{17}$ used varying sample sizes from 10-88 COPD patients. Thus, we enrolled 94 subjects, and considered that the matched data from the returning 58 COPD patients who had both baseline and one-year measurements was an adequate sample size for this study.

\section{Results}

The study population was composed of 58 subjects, with 40 patients categorized as GOLD stage 2, 15 patients as stage 3 , and 3 patients at stage 4 (see Table 1 for demography). $\mathrm{FEV}_{1}$ percent predicted did not change over the one-year period (mean 56.7 vs 57.5, p=0.1) (Figure 1) and neither did BMI (mean 27.45 vs 27.31, p=0.4). Table 2 shows the baseline and one-year values for other pulmonary function tests. Peripheral blood samples were obtained from all 58 patients at both visits.

\section{Repeatability of systemic biomarkers}

Table 3 summarizes the measurements of the systemic inflammatory biomarkers and BMI at the baseline and oneyear visit. Using paired $\mathrm{T}$ tests there was no statistically significant change in these measurements between both visits ( $p>0.05$ for all comparisons).

Using ICC analysis, there was moderate agreement with a very high degree of statistical significance $(\mathrm{p} \leq 0.001)$ between the two visits for all the systemic biomarkers (IL-6, CRP, and TNF- $\alpha$ ). Graphical representations of the repeatability of systemic biomarkers using the Bland - Altman methods are shown in Figure 2. These plots indicate moderate reproducibility, as the mean differences of the repeated measurements lie close to zero and all values
Table I Baseline characteristics of the study patients

\begin{tabular}{ll}
\hline Characteristic & $\mathbf{n}=\mathbf{5 8}$ COPD \\
\hline Age (years) & $63.78(8.32)$ \\
Gender, male/female & $40 / 18$ \\
Current/Ex-smokers & $23 / 35$ \\
Pack year history & \\
Inhaled steroids use/no use & $42.5(36-53.5)$ \\
Long acting beta agonist use & 31 \\
Long acting anticholinergic use & 27 \\
Methylxanthines use & 10 \\
Pre-bronchodilator FEV, \% predicted & 5 \\
Pre-bronchodilator FVC \% predicted & $56.71(13.11)$ \\
Post-bronchodilator FEV, \% predicted & $93.64(17.77)$ \\
Post bronchodilator FEV, (L) & $64.09(14.16)$ \\
Post bronchodilator FEV,/FVC ratio (\%) & $1.79(0.6)$ \\
\hline
\end{tabular}

Abbreviations: COPD, chronic obstructive pulmonary disease; FEV , forced expiratory volume in one second; FVC, forced vital capacity; IQR, interquartile range; $\mathrm{SD}$, standard deviation.

Notes: Lung function measurements were standardized for age and gender. There were no patients on oral corticosteroids. Results presented as mean (SD) or median (IQR).

are randomly scattered around the mean difference with the majority of values lying within the limits of agreement ( \pm 2 SD). Antilogging the limits for IL-6, CRP, and TNF- $\alpha$ show that $95 \%$ of cases for the one-year measurement will have at least a 3.8-, 5.2-, and 2.8-fold change from the baseline measurement, respectively.

\section{Relationships between systemic biomarkers}

CRP was significantly associated with IL-6 at the baseline and one-year visits $(\mathrm{r}=0.55, \mathrm{p}=0.0001, \mathrm{r}=0.51, \mathrm{p}=0.0002$, respectively) (Figures 3a, 3b). There were no other significant associations between the systemic markers at either of the visits (Tables 4a, 4b).

\section{Discussion}

The main novelty of this study is the repeatability of systemic biomarkers in a moderate to severe COPD population over one-year. IL-6, CRP, and TNF- $\alpha$ showed moderate repeatability over one year. We also found a moderate association between CRP and IL-6, confirming the results of previous studies, ${ }^{2,3,19,20}$ but no association between these proteins and TNF- $\alpha$, in contrast to previous reports. ${ }^{3,19,23}$

The repeatability of systemic inflammatory biomarkers over 12 months in COPD patients was analyzed by three statistical methods; first, we observed no significant changes in group mean values for any of the measurements. 


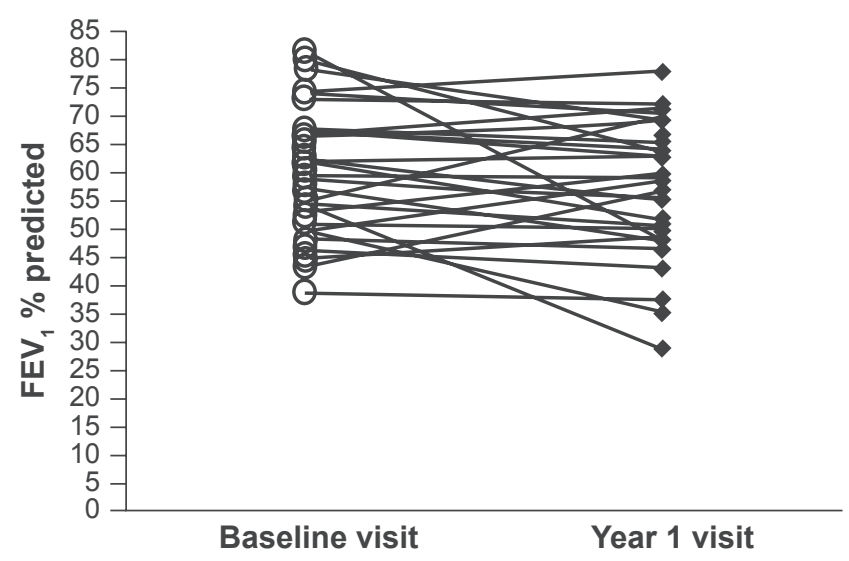

Figure I FEV, \% predicted for each patients at the baseline and year I visit.

Second, using ICC, which is a recognized method for assessing the repeatability of measurements, we observed moderate levels of agreement for systemic inflammatory markers, as the $R_{i}$ values were $\geq 0.5$. Third, we also present Bland - Altman plots to view the repeatability of data from individual subjects. To our knowledge, this is the first study to compare the long term reproducibility of IL-6 and TNF- $\alpha$ in COPD patients, and we demonstrate moderate repeatability for these systemic biomarkers over a 12 month period.

It has previously been shown that CRP did not change over a 17 month interval, ${ }^{17}$ but we are not aware of any similar information concerning IL- 6 and TNF- $\alpha$. The assessments of repeatability in our study can be used in the following ways; the within-subject SDs can be used to aid the statistical powering of clinical trials with pharmacological interventions and the Bland-Altman plots show the variation that could be expected for individual measurements in clinical practice.
The systemic biomarkers that we investigated all appear to be related to pathophysiological processes in COPD; CRP is related to cardiovascular risk ${ }^{15,16}$ and has been shown to be associated with many other important clinical outcomes of COPD. For example previous studies have been shown CRP to be related to the symptom domain of St George's Respiratory Questionnaire (SGRQ), impaired energy metabolism, and muscle strength. ${ }^{2,3,17}$ IL-6 is known as a powerful promoter of CRP production in the liver ${ }^{18}$ and is associated with CRP levels in COPD patients, ${ }^{2,3,6,19}$ whilst TNF- $\alpha$ and its receptors are increased in the muscles of COPD patients thus implicating it in conditions such as cachexia in COPD. ${ }^{4,31,32}$

The present study confirms that the link between IL- 6 and CRP exists in our group of moderate to severe COPD patients and that it is a robust relationship that does not change over one year. The moderate association $(r=0.51-0.55)$ on two occasions adds confidence to our interpretation that IL-6 promotes CRP production in COPD patients.

The finding that neither IL-6 nor CRP was related to the TNF- $\alpha$ is in contrast to two previous studies that showed a relationship, albeit a weak correlation, between TNF- $\alpha$ and IL- $6^{3,19}$ and TNF- $\alpha$ and CRP existed ${ }^{3}$ in COPD patients. One methodological explanation for the lack of correlation in the current study could be due to the short half life of TNF- $\alpha$ compared to IL-6 or CRP. TNF- $\alpha$ has a short half-life of a few minutes and is also difficult to detect because it forms complexes with soluble TNF- $\alpha$ receptors (sTNF-R) and has high renal clearance. ${ }^{33,34}$ Circulating sTNF-R may be a more sensitive marker of TNF- $\alpha$ activation as they have slower renal clearance. ${ }^{33,34}$ Increased levels of these soluble receptors have been detected in COPD patients. ${ }^{11,21}$ In addition the current study population consisted mainly of moderate

Table 2 Pulmonary function at the baseline visit and one-year visit

\begin{tabular}{|c|c|c|}
\hline Pulmonary function & Baseline & Year I \\
\hline Pre-bronchodilator $\mathrm{FEV}, \%$ predicted & $56.7 \mid(\mid 3.1)$ & $57.49(\mid 3.2)$ \\
\hline Post-bronchodilator FEV $\%$ predicted & $64.09(14.2)$ & $63.63(14.9)$ \\
\hline $\operatorname{Raw}^{\mathrm{a}}(\mathrm{kPa} . \mathrm{sec})$ & $0.46(0.4-0.5)$ & $0.47(0.4-0.5)$ \\
\hline $\mathrm{sGaw}^{\mathrm{a}}$ (kPa.sec) & $0.46(0.4-0.5)$ & $0.47(0.4-0.5)$ \\
\hline FRC (\% predicted) & $132.02(29.0)$ & $128.17(30.5)$ \\
\hline IC (L) & $2.33(0.6)$ & $2.40(0.6)$ \\
\hline TLC $\%$ predicted & $106.44(16.2)$ & $103.11(15.2)$ \\
\hline RV \% predicted & | $47.27(35.8)$ & $131.16(4 \mid .3)$ \\
\hline KCO \% predicted & $89.49(25.1)$ & $89.08(24.8)$ \\
\hline
\end{tabular}

Abbreviations: $\mathrm{Cl}$, confidence interval; $\mathrm{FEV}_{1}$, forced expiratory volume in one second; $\mathrm{FRC}$, functional residual capacity; IC, inspiratory capacity; $\mathrm{KCO}$, carbon monoxide diffusion factor; Raw, airways resistance; RV, residual volume; SD, standard deviation; sGaw, specific airways conductance; TLC, total lung capacity.

Notes: Lung function measurements were standardized for age and gender. There were no patients on oral corticosteroids. Results presented as mean (SD) or geometric mean $(95 \% \mathrm{Cl})$. 
Table 3 Repeatability of systemic measurements over the one year interval

\begin{tabular}{lllll}
\hline Systemic indices & Baseline & Year I & p value & R and p value \\
\hline IL-6 $(\mathrm{pg} / \mathrm{ml})$ & $3.2(2.5-4.1)$ & $3.1(2.6-3.7)$ & 0.75 & 0.500 .00 I \\
CRP $(\mathrm{pg} / \mathrm{ml})$ & $3.3(2.5-4.4)$ & $2.9(2.3-3.6)$ & 0.57 & $0.57<0.000$ I \\
TNF- $\alpha(\mathrm{pg} / \mathrm{ml})$ & $1.8(1.6-2.0)$ & $1.6(1.4-1.9)$ & $0.4 \mathrm{I}$ & $0.57<0.000$ I \\
\hline
\end{tabular}

Abbreviations: CRP, C-reactive protein; IL-6, interleukin-6; TNF- $\alpha$, tumor necrosis factor- $\alpha$.

Note: Data presented as geometric mean $(95 \% \mathrm{Cl})$.

COPD patients and a different relationship to TNF- $\alpha$ may have been observed in a population consisting of a range of disease severities.

BMI is recognized as an important tool in defining phenotypes of COPD patients and a reduced BMI has been shown to be an independent risk factor for mortality in COPD and to be associated with disease severity. ${ }^{35,36}$ Increased skeletal muscle apoptosis have also been shown to be associated with a lower BMI and reduced exercise tolerance. ${ }^{5}$ In our study BMI was not related to circulating levels of IL-6, CRP, and TNF- $\alpha$. This suggests that body mass loss may not be caused through systemic inflammation. However, there are studies that have shown CRP and BMI to be associated to each other. ${ }^{2,4,17}$ These findings were found in severe COPD patients with $\mathrm{FEV}_{1}<40 \%$ in comparison to the current study population comprised mainly of moderate disease. Although, in one recent study by Karadag and colleagues ${ }^{37}$ moderate patients were grouped into low BMI and normal-to-high BMI and they showed that the low BMI patients had higher levels of CRP and TNF- $\alpha$. Conversely, in our population of patients we did not observe significant weight loss in individual patients over one-year, with our mean values of BMI being $>25 \mathrm{~kg} / \mathrm{m}^{2}$ at both visits. This perhaps could also account for the lack of correlation observed between change in BMI and inflammatory biomarkers.

TNF- $\alpha$ and IL- 6 levels have been shown to be increased in weight losing COPD patients ${ }^{4,9}$ However the present study does not support this finding. In the study by Eid and colleagues, ${ }^{4}$ weight loss characterized by reduced fat free mass (FFM) and skeletal muscle mass was associated with increased systemic inflammatory response. They showed that TNF- $\alpha$, sTNF-R, and IL- 6 were inversely related to FFM in patients with normal BMI. Another study also showed that CRP was inversely related to FFM in hypermetabolic patients. ${ }^{8}$ FFM appears to be a better marker of weight loss compared to BMI, particularly since FFM has been shown to be a predictor of mortality in the presence of normal BMI. ${ }^{38} \mathrm{BMI}$ has the advantage of being easy to measure but is a limited value as it does not a)

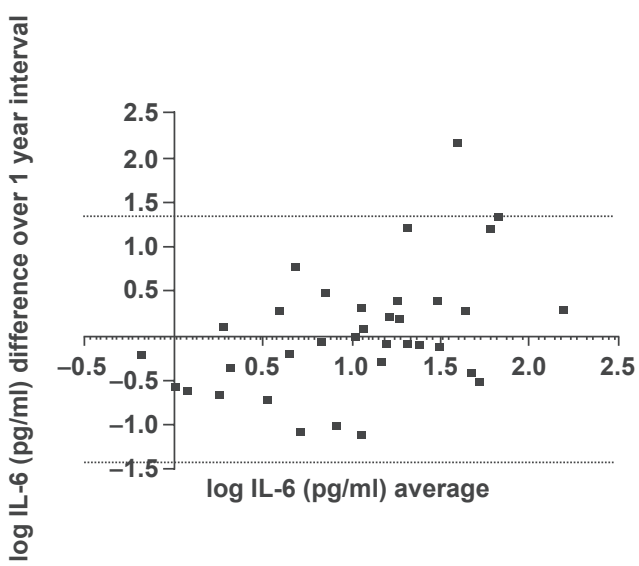

b)

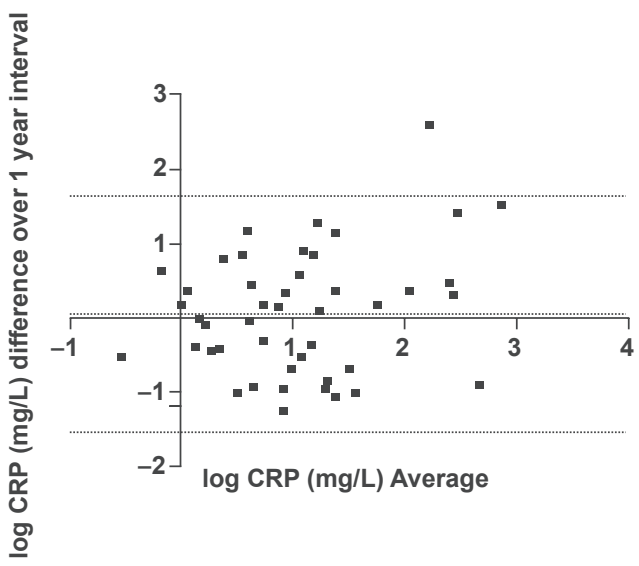

c)

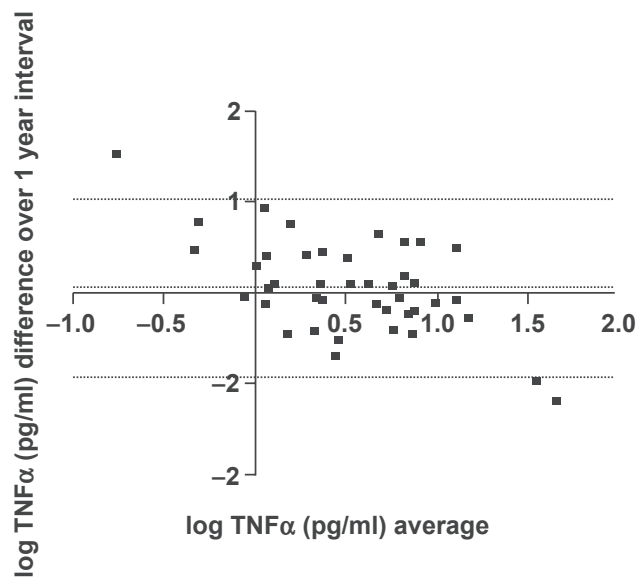

Figure 2 Bland-Altman plots for a) IL-6, b) CRP and c)TNF $\alpha$ collected with a one year interval. The dotted lines represent the mean difference \pm 2 SD.

Abbreviations: CRP, C-reactive protein; IL, interleukin; TNF $\alpha$, tumor necrosis factor- $\alpha$. 


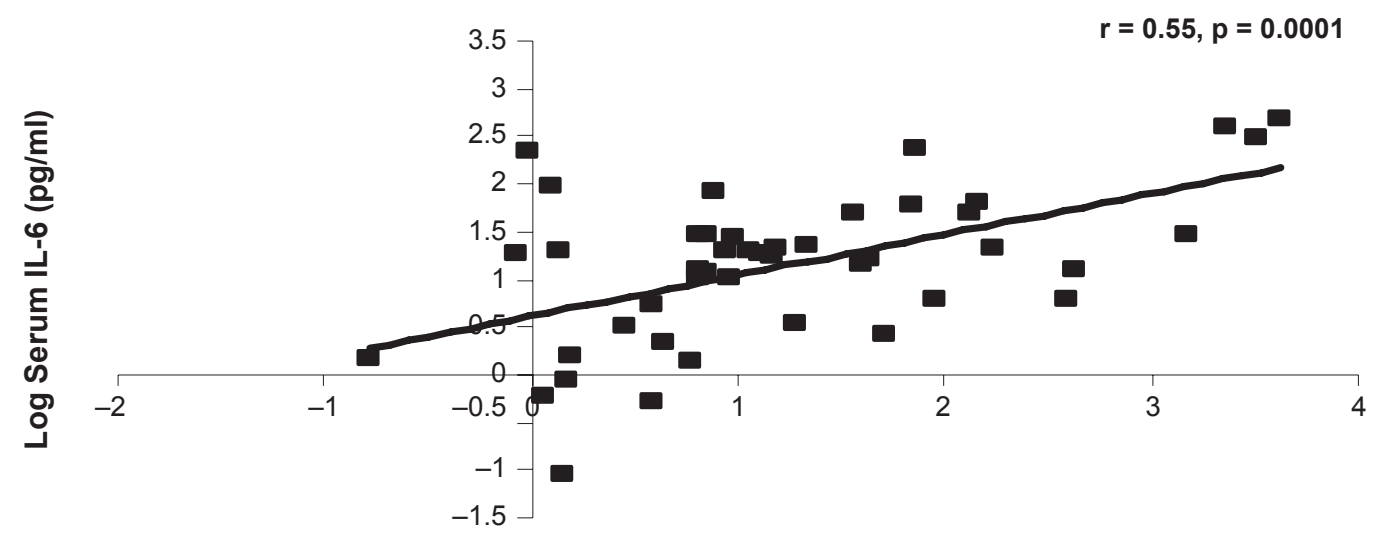

Log Plasma CRP (mg/L)

Figure 3a The relationship between CRP and IL-6 at the baseline visit. Abbreviations: CRP, C-reactive protein; IL-6, interleukin-6.

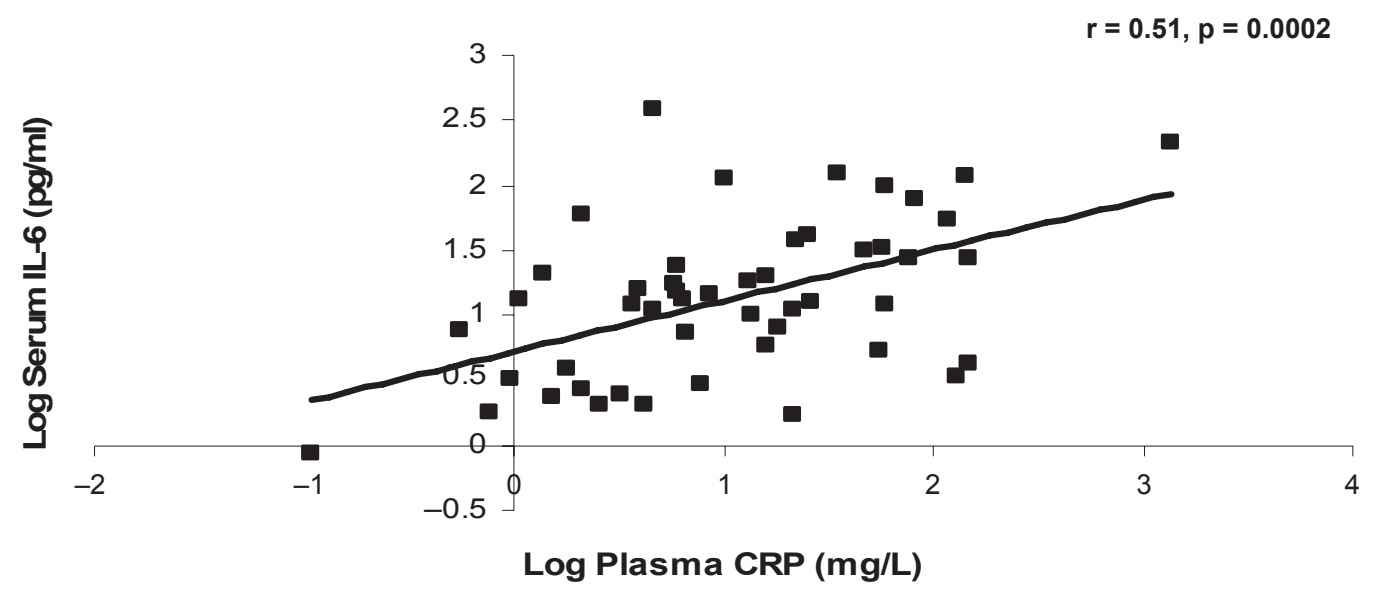

Figure 3b The relationship between CRP and IL-6 at the one-year visit. Abbreviations: CRP, C-reactive protein; IL-6, interleukin-6.

represent changes in body composition or reflect skeletal muscle depletion.

The limitations of our study are: (a) we did not measure many other systemic biomarkers that may be of interest in COPD due to limited resources and therefore we decided to

Table 4a Relationships between systemic inflammatory biomarkers and $\mathrm{BMI}$ at the baseline visit

\begin{tabular}{llll}
\hline & CRP & TNF- $\alpha$ & BMI \\
\hline IL-6 & $r=0.55, p=0.000 I$ & $r=0.1 I, p=0.47$ & $r=-0.10, p=0.49$ \\
CRP & & $r=0.18, p=0.20$ & $r=0.18, p=0.22$ \\
TNF- $\alpha$ & & & $r=-0.11, p=0.44$ \\
\hline
\end{tabular}

Abbreviations: BMI, body mass index; CRP, C-reactive protein; IL-6, interleukin-6; TNF- $\alpha$, tumor necrosis factor- $\alpha$. measure IL-6, CRP, and TNF- $\alpha$ because of their potential role in the pathopyhysiology of COPD; (b) we measured our samples only once at enrollment and at 12 months. It would have been of interest to have performed "serial sampling"; a recent study ${ }^{39}$ using 11 visits performed over

Table 4b Relationships between systemic inflammatory biomarkers and $\mathrm{BMI}$ at the one-year visit

\begin{tabular}{llll}
\hline & CRP & TNF- $\alpha$ & BMI \\
\hline IL-6 & $r=0.5 I, p=0.0002$ & $r=0.18, p=0.23$ & $r=0.25, p=0.09$ \\
CRP & & $r=-0.1 I, p=0.4 I$ & $r=0.26, p=0.06$ \\
TNF- $\alpha$ & & & $r=-0.20, p=0.16$ \\
\hline
\end{tabular}

Abbreviations: BMI, body mass index; CRP, C-reactive protein; IL-6, interleukin-6; TNF- $\alpha$, tumor necrosis factor- $\alpha$. 
a one-month interval to assess inflammatory biomarkers suggests that intra-patient variability is reduced with the use of a "rolling mean" of serial samples; (c) our population was composed of mainly moderate-to-severe disease, and the inclusion of more very severe patients would have been of interest especially to examine the repeatability by different GOLD severities; (d) we did not capture any clinical changes such as exacerbation within in the oneyear interval excluding the four-week interval leading up to their study visit which may have influenced our results; (e) we were unable to perform analysis related to changes in therapeutic regime as we were limited by numbers of patients that had actually had a change in their medications such as stopping/starting inhaled corticosteroids (ICS) by the one-year visit. Although, it has recently been confirmed by $\mathrm{Sin}$ and colleagues ${ }^{40}$ and Kuniaski and colleagues ${ }^{20}$ that ICS use does not affect IL-6 and CRP levels measured; and (f) we did not relate our findings to other clinical parameters of COPD such as partial pressure of oxygen in arterial blood, exercise tolerance, and health status over an one-year interval.

In conclusion, the systemic inflammatory biomarkers IL-6, CRP, and TNF- $\alpha$ were moderately repeatable over a 12 month period in COPD patients. We have also shown that a robust and repeatable association between IL-6 and CRP exists. However, there was a lack of correlation of TNF- $\alpha$ to IL-6 or CRP, possibly due to the instability of TNF- $\alpha$, or perhaps because TNF- $\alpha$ genuinely plays a different role to IL-6 and CRP in the pathophysiology of COPD.

\section{Disclosure}

The authors report no conflicts of interest in this work.

\section{References}

1. Global Initiative for Chronic Obstructive Lung Disease (GOLD). 2007. Accessed March 28, 2007. Available from http://www.goldcopd.com.

2. Broekhuizen R, Wouters EF, Creutzberg EC, Schols AM. Raised CRP levels mark metabolic and functional impairment in advanced COPD. Thorax. 2006;61(1):17-22.

3. Yende S, Waterer GW, Tolley EA, et al. Inflammatory markers are associated with ventilatory limitation and muscle dysfunction in obstructive lung disease in well functioning elderly subjects. Thorax. 2006;61(1):10-16.

4. Eid AA, Ionescu AA, Nixon LS, et al. Inflammatory response and body composition in chronic obstructive pulmonary disease. Am J Respir Crit Care Med. 2001;164(8 Pt 1):1414-1418.

5. Agusti AG, Sauleda J, Miralles C, et al. Skeletal muscle apoptosis and weight loss in chronic obstructive pulmonary disease. Am J Respir Crit Care Med. 2002;166(4):485-489.

6. Sin DD, Man SF. Why are patients with chronic obstructive pulmonary disease at increased risk of cardiovascular diseases? The potential role of systemic inflammation in chronic obstructive pulmonary disease. Circulation. 2003;107(11):1514-1519.
7. Jorgensen NR, Schwarz P, Holme I, Henriksen BM, Petersen LJ, Backer V. The prevalence of osteoporosis in patients with chronic obstructive pulmonary disease: a cross sectional study. Respir Med. 2007;101(1):177-185.

8. Schols AM, Buurman WA, Staal van den Brekel AJ, Dentener MA, Wouters EF. Evidence for a relation between metabolic derangements and increased levels of inflammatory mediators in a subgroup of patients with chronic obstructive pulmonary disease. Thorax. 1996;51(8): 819-824.

9. de Godoy I, Donahoe M, Calhoun WJ, Mancino J, Rogers RM. Elevated TNF-alpha production by peripheral blood monocytes of weight-losing COPD patients. Am J Respir Crit Care Med. 1996;153(2):633-637.

10. Gan WQ, Man SF, Senthilselvan A, Sin DD. Association between chronic obstructive pulmonary disease and systemic inflammation: a systematic review and a meta-analysis. Thorax. 2004;59(7):574-580.

11. Takabatake N, Nakamura H, Abe S, et al. Circulating leptin in patients with chronic obstructive pulmonary disease. Am J Respir Crit Care Med. 1999;159(4 Pt 1):1215-1219.

12. Higashimoto Y, Yamagata Y, Taya S, et al. Systemic inflammation in chronic obstructive pulmonary disease and asthma: Similarities and differences. Respirology. 2008;13(1):128-133.

13. Dahl M, Vestbo J, Lange P, Bojesen SE, Tybjaerg-Hansen A, Nordestgaard BG. C-reactive protein as a predictor of prognosis in chronic obstructive pulmonary disease. Am J Respir Crit Care Med. 2007;175(3):250-255.

14. Man SF, Connett JE, Anthonisen NR, Wise RA, Tashkin DP, Sin DD. C-reactive protein and mortality in mild to moderate chronic obstructive pulmonary disease. Thorax. 2006;61(10):849-853.

15. Pearson TA, Mensah GA, Alexander RW, et al. Markers of inflammation and cardiovascular disease: application to clinical and public health practice: A statement for healthcare professionals from the Centers for Disease Control and Prevention and the American Heart Association. Circulation. 2003;107(3):499-511.

16. Ridker PM, Rifai N, Rose L, Buring JE, Cook NR. Comparison of C-reactive protein and low-density lipoprotein cholesterol levels in the prediction of first cardiovascular events. $N$ Engl $J$ Med. 2002;347(20):1557-1565.

17. Pinto-Plata VM, Mullerova H, Toso JF, et al. C-reactive protein in patients with COPD, control smokers and non-smokers. Thorax. 2006;61(1):23-28.

18. Kishimoto T. The biology of interleukin-6. Blood. 1989;74(1):1-10.

19. Garrod R, Marshall J, Barley E, Fredericks S, Hagan G. The relationship between inflammatory markers and disability in chronic obstructive pulmonary disease (COPD). Prim Care Respir J. 2007;16(4): 236-240.

20. Kunisaki KM, Rice KL, Janoff EN, Rector TS, Niewoehner DE. Exhaled nitric oxide, systemic inflammation, and the spirometric response to inhaled fluticasone propionate in severe chronic obstructive pulmonary disease: a prospective study. Ther Adv Respir Dis. 2008;2(2):55-64.

21. Takabatake N, Nakamura $\mathrm{H}$, Abe $\mathrm{S}$, et al. The relationship between chronic hypoxemia and activation of the tumor necrosis factor-alpha system in patients with chronic obstructive pulmonary disease. Am J Respir Crit Care Med. 2000;161(4 Pt 1):1179-1184.

22. Di Francia M, Barbier D, Mege JL, Orehek J. Tumor necrosis factoralpha levels and weight loss in chronic obstructive pulmonary disease. Am J Respir Crit Care Med. 1994;150(5 Pt 1):1453-1455.

23. Karadag F, Karul AB, Cildag O, Yilmaz M, Ozcan H. Biomarkers of systemic inflammation in stable and exacerbation phases of COPD. Lung. 2008;186(6):403-409.

24. Lee TM, Lin MS, Chang NC. Usefulness of C-reactive protein and interleukin-6 as predictors of outcomes in patients with chronic obstructive pulmonary disease receiving pravastatin. Am J Cardiol. 2008;101(4):530-535.

25. Beeh KM, Beier J, Kornmann O, Mander A, Buhl R. Long-term repeatability of induced sputum cells and inflammatory markers in stable, moderately severe COPD. Chest. 2003;123(3):778-783. 
26. Balzano G, Stefanelli F, Iorio C, et al. Eosinophilic inflammation in stable chronic obstructive pulmonary disease. Relationship with neutrophils and airway function. Am J Respir Crit Care Med. 1999;160(5 Pt 1):1486-1492.

27. Brightling CE, Monterio W, Green RH, et al. Induced sputum and other outcome measures in chronic obstructive pulmonary disease: safety and repeatability. Respir Med. 2001;95(12):999-1002.

28. Boorsma M, Lutter R, van de Pol MA, Out TA, Jansen HM, Jonkers RE. Repeatability of inflammatory parameters in induced sputum of COPD patients. COPD. 2007;4(4):321-329.

29. Peleman RA, Rytila PH, Kips JC, Joos GF, Pauwels RA. The cellular composition of induced sputum in chronic obstructive pulmonary disease. Eur Respir J. 1999;13(4):839-843.

30. Bland JM, Altman DG. Statistical methods for assessing agreement between two methods of clinical measurement. Lancet. 1986;1(8476):307-310.

31. Sevenoaks MJ, Stockley RA. Chronic Obstructive Pulmonary Disease, inflammation and co-morbidity - a common inflammatory phenotype? Respir Res. 2006;7:70.

32. Reid MB, Li YP. Tumor necrosis factor-alpha and muscle wasting: a cellular perspective. Respir Res. 2001;2(5):269-272.

33. Bemelmans MH, van Tits LJ, Buurman WA. Tumor necrosis factor: function, release and clearance. Crit Rev Immunol. 1996; 16(1):1-11.
34. Diez-Ruiz A, Tilz GP, Zangerle R, Baier-Bitterlich G, Wachter H, Fuchs D. Soluble receptors for tumour necrosis factor in clinical laboratory diagnosis. Eur J Haematol. 1995;54(1):1-8.

35. Landbo C, Prescott E, Lange P, Vestbo J, Almdal TP. Prognostic value of nutritional status in chronic obstructive pulmonary disease. Am J Respir Crit Care Med. 1999;160(6):1856-1861.

36. Schols AM, Slangen J, Volovics L, Wouters EF. Weight loss is a reversible factor in the prognosis of chronic obstructive pulmonary disease. Am J Respir Crit Care Med. 1998;157(6 Pt 1):1791-1797.

37. Karadag F, Kirdar S, Karul AB, Ceylan E. The value of C-reactive protein as a marker of systemic inflammation in stable chronic obstructive pulmonary disease. Eur J Intern Med. 2008;19(2):104-108.

38. Vestbo J, Prescott E, Almdal T, et al. Body mass, fat-free body mass, and prognosis in patients with chronic obstructive pulmonary disease from a random population sample: findings from the Copenhagen City Heart Study. Am J Respir Crit Care Med. 2006;173(1):79-83.

39. Sapey E, Bayley D, Ahmad A, Newbold P, Snell N, Stockley RA. Inter-relationships between inflammatory markers in patients with stable COPD with bronchitis: intra-patient and inter-patient variability. Thorax. 2008;63(6):493-499.

40. Sin DD, Man SF, Marciniuk DD, et al. The effects of fluticasone with or without salmeterol on systemic biomarkers of inflammation in chronic obstructive pulmonary disease. Am J Respir Crit Care Med. 2008;177(11):1207-1214. 